\title{
Ch-ch-ch-ch- changes
}

\author{
Ann K. G. Brown \\ Correspondence to this column should be addressed \\ to Ann K. G. Brown, Research and User Services \\ Librarian and Workshop Coordinator, George \\ Washington University, Libraries and Academic \\ Innovation; e-mail:agbrown@gwu.edu.
} summer as I sit down to complete this column. And as such, my tenure as Reference and User Services Association President is coming to an end and President-Elect Beth German is poised to assume the position and this column!

As with our day-to-day profession, ALA and RUSA have seen their share of challenges and changes in this past year. The Steering Committee on Organizational Effectiveness (SCOE) is looking at sweeping changes to the structure of ALA, including the divisions. Our efforts of focusing on equity, diversity, and inclusion continues to be a challenge organizationally and professionally for libraries, library workers, and their patrons.

Those at the front lines of reference and user services are seeing a transformation of their work. Knowing this, RUSA is changing its strategic direction to be more proactive and nimbler. Since September 2018, RUSA's board of directors has been working diligently to create a new mission statement and strategic plan, specifically using an appreciative inquiry approach. ${ }^{1}$ This approach really changed how we worked together and helped us understand what it means to be the board of directors at a nonprofit. This was a major philosophical shift for us. As a result, we created a guiding document, the RUSA Cultural Norms, ${ }^{2}$ as a way to guide us in our work with each other.

We circulated a survey asking library workers what excited them about reference and user services and received nearly 400 responses! We used those results to identify trends and areas that could be used by RUSA to guide our strategic direction. That work then melded into the board members reflecting on their stories of why they made RUSA their home in the ALA. It was intriguing to see how those stories tied directly with the trends we identified in the broader survey.

All of this culminated in our new mission statement:

The Reference and User Services Association is a network to educate, empower, and inspire its members to advance the evolution of the profession and better serve users in a continuously changing information society.

RUSA is here to lead the way as we gain understanding of what reference and user services is both to our profession and our volunteer members. While changes can be challenging, know you can rely on this division and member network to help you meet the challenges and lead the way. 


\section{References}

1. The David L. Cooperrider Center for Appreciative Inquiry at Champlain College, "Introduction to Appreciative Inquiry," The Appreciative Inquiry Commons, accessed May 14, 2019, https:// appreciativeinquiry.champlain.edu/learn/appreciative-inquiry -introduction.

2. Melissa Vanyek, "RUSA Cultural Norms," RUSA Update, 2019, accessed May 14, 2019, https://rusaupdate.org/2019/01/rusa -cultural-norms. 